\title{
Genetic parameters for longevity measures in Brazilian Holstein cattle using linear and threshold models
}

\author{
Elisandra Lurdes Kern', Jaime Araujo Cobuci', Cláudio Napolis Costa², José Braccini Neto', \\ Gabriel Soares Campos ${ }^{3}$ and Concepta Margaret McManus M $^{4,5}$ \\ ${ }^{1}$ Departamento de Zootecnia, Universidade Federal do Rio Grande do Sul (UFRGS), Porto Alegre, Brasil, ${ }^{2}$ Embrapa Gado \\ de Leite, Juiz de Fora, Brasil, ${ }^{3}$ Departamento de Zootecnia, Universidade Federal de Pelotas (UFPEL), Pelotas, Brasil, \\ ${ }^{4}$ Universidade de Brasília, Brasília, Brasil, ${ }^{5}$ Instituto Nacional de Ciência e Tecnologia-Informação Genético-Sanitária da \\ Pecuária Brasileira (MCT/CNPq/FAPEMIG), Belo Horizonte, Brasil
}

\begin{abstract}
The aim in this study was to estimate variance components and heritability of different longevity measures related to productive life and survival at a specified age, using linear and threshold models, to specify the more appropriate measure to express longevity in Brazilian Holstein cows. Production and reproduction records of Holstein cows were collected from 1991 to 2010, for cows born between 1987 and 2006. Variance components were obtained by restricted maximum likelihood (REML) for measures of productive life and a Bayesian analysis for survival measures. The heritability estimates for longevity measures ranged from 0.06 to 0.09 , using the linear model and from 0.05 to 0.18 for traits using the threshold model. This suggests an inexpressive genetic gain using selection for these traits, whereas improvements in environmental factors which affect these animals may lead to greater phenotypic gains. Survival up to 48 months from first calving was the measureing point defined as the most appropriate to be included in future official genetic evaluations of Holstein cattle in Brazil.
\end{abstract}

Keywords: Bayesian method, REML method, survival in herd, productive life

Abbreviations: CG: Contemporary groups, D: Disconnected groups; REML: restricted maximum likelihood

Archiv Tierzucht 57 (2014) 33, 1-12

doi: 10.7482/0003-9438-57-033

Corresponding author:

Elisandra Lurdes Kern; email: elikern@hotmail.com

Universidade Federal do Rio Grande do Sul Departamento de Zootecnia, Faculdade de Agronomia, Avenida Bento Gonçalves 7712, 91540-000 Porto Alegre, RS, Brasil
Received: 22 September 2013 Accepted: 13 January 2014 Online: 14 November 2014
@ 2014 by the authors; licensee Leibniz Institute for Farm Animal Biology (FBN), Dummerstorf, Germany.

This is an Open Access article distributed under the terms and conditions of the Creative Commons Attribution 3.0 License (http://creativecommons.org/licenses/by/3.0/). 


\section{Introduction}

Selection of dairy cattle in Brazil has focused on productive characteristics such as milk production for many years. This has led to a reduction in the genetic merit of reproductive, health and longevity characteristics (Wall et al. 2005, Pérez-Cabal et al. 2006), and has had direct economic impacts on the production system. Longevity is determined by decisions related to voluntary culling of cows, based on their milk production, or involuntary culling, due to problems related to locomotion, reproduction and health (Berry et al. 2005). A decrease in involuntary culling, as well as reducing costs of cow replacement, can lead to an increase in selection intensity for milk production, resulting in greater genetic gain due to the higher chance of voluntary disposals (Logrotta et al. 2010).

Different measures for longevity have been reported in the literature, such as length of productive life, total milk production, herd life, total number of lactations and survival observed at a certain age, measured from birth or after first calving (Vacek et al. 2006).

Direct selection for longevity may be limited due to the amount of time needed to obtain the measurement. Longevity can be measured up to a certain point in life, culling or death of the animal and is characterized by low heritability ( 0.03 to 0.10$)$, particularly when assessed by a linear model (Vollema \& Groen 1996, Cruickshank et al. 2002, Tsuruta et al. 2005, Daliri et al. 2008). However, higher heritability has been reported for measures of survival when evaluated by the threshold model (Queiroz et al. 2007, Ahlman et al. 2011), which may contribute to an acceleration in the response to selection for longevity.

Given the economic importance of this trait for the dairy industry and considering the few studies available with the Holstein breed in Brazil, this work aimed to estimate variance components and heritability for different measures of longevity using both linear and threshold models, to identify the most appropriate measure to be used in future official genetic evaluations for the Holstein breed in Brazil.

\section{Material and methods}

Production and reproduction records of Holstein cows collected by the Dairy and Herd Control of the Brazilian Association of Holstein Cattle Breeders - ABCBRH and its state affiliates, from 1991 to 2010 were used, relative to cows born between 1987 and 2006.

Production and reproduction data were used to calculate measures of longevity related to productive life: total milk production in all lactations, in kilograms (Long1), number of lactations initiated (Long2), total milking days (Long3); time from birth to last milk recording, in months (Long4), time from first calving to the last milk recording, in months (Long5), and measures related to survival from birth to 36 (Long6_36), 48 (Long6_48), 60 (Long6_60) 72 (Long6_72) and 84 (Long6_84) months of age, as well as survival to 12 (Long7_12), 24 (Long7_24), 36 (Long7_36), 48 (Long7_48) and 54 (Long7_54) months after first calving.

Survival measures were defined assuming success (1) for cows that remained in the herd and failure (0) for those which were no longer in the herd at stipulated ages.

To maintain consistency of longevity measures, cows that could still be alive at the time of analyses were excluded from the dataset. Two criteria were used to verify whether the cows were still alive in the herd. The first was the presence of the last date of milk recording and 
the second consisted of the difference between the date of the cow's last calving (up to the time of data collection for each cow) and the date of the latest calving on each farm. When this difference was less than 24 months the cow was considered to be alive. The 24 month period was used because about $95 \%$ of this population showed a new calving during this period. This criterion was also used by Caetano et al. (2011) in Nelore cows.

To ensure that cows had the opportunity to express the phenotype for survival measures, females born after 2005, 2004, 2003 and 2002 were excluded for Long6_48, Long6_60, Long6_72 and Long6_84, respectively. Further cows were also excluded for specific measures: females born in 2006 and 2005 that had their first calving after 24 and 36 months, respectively (Long7_24); all females born in 2006 and those born in 2005 that had their first calving after 24 months of age (Long7_36); all females born in 2005 and those born in 2004 with first calving after 24 months of age (Long7_48); and all females born in 2004 and those born in 2003 that had their first calving after 24 months of age (Long7_54).

Contemporary groups (CG) were formed for the different measures of longevity. For survival measures, CG were defined by herd and year of first calving. For the other measures it was defined by herd, year and season of first calving. The seasons were defined as: summer (January to March), autumn (April to June), winter (July to September) and spring (October to December). For the longevity analysis, milk production in the first lactation and age at first calving were divided into four classes. The classes of milk production in the first lactation were: up to $6.500 \mathrm{~kg}, 6.501$ to $7.750 \mathrm{~kg}, 7.751$ to 9.000 and greater than $9.001 \mathrm{~kg}$ milk and the classes for age at first calving were: up to 24 months, 25 to 26 months, 27 to 29 months and greater than 29 months of age.

Bulls had at least two daughters in two different herds and CG had at least five records. A connectability test was performed among contemporary groups using the software AMC (Roso \& Schenkel 2006) and groups with no genetic connection were excluded (Table 1). For survival measures, groups without variation were excluded, that is, containing a single score (0 or 1) as proposed by Harville \& Mee (1984). The number of cows, bulls, cow dams, herds and contemporary groups for longevity measures are shown in Table 1.

Estimates of (co)variance related to productive life were performed using the restricted maximum likelihood derivative free method in MTDFREML (Boldman et al. 1995). A convergence criterion of 10-9 was used, restarting the analysis at each convergence, using the final values of the previous analysis as initial values in the new analysis of (co)variance until no further difference existed in the four decimal values of -2 log likelihood between two successive analyses.

For survival measures, the variance components were estimated by Bayesian inference using the program THRGIBBS1F90 (Misztal et al. 2002), with a univariate threshold animal model. The THRGIBBS1F90 program generates Markov chains for the model parameters through the Gibbs sampler. A uniform prior distribution was used for the fixed effects and an inverted Wishart prior distribution (variance components) with a minimum degree of confidence for the random effects.

Analyses of survival measures consisted of a chain of 800000 cycles with burn-in of 240000 cycles. A sample was withdrawn every 60 iterations resulting in 9333 samples used for parameter estimation. Convergence was verified through the R program using Geweke's (1992) and Heidelberger \& Welch (1983) diagnostics, from the Bayesian Output Analysis 
Program - BOA (Smith 2005). A posteriori estimates were obtained using POSTGIBBSF90 (Misztal et al. 2002).

Table 1

Number of cows, bulls, cow dams, herds, contemporary groups and disconnected groups for longevity measures

\begin{tabular}{lcccccc}
\hline Measures & Cows & Bulls & Cow dams & Herds & $\begin{array}{c}\text { Contemporary } \\
\text { groups }\end{array}$ & $\begin{array}{c}\text { Disconnected } \\
\text { groups }\end{array}$ \\
\hline Long1 & 69315 & 1890 & 45039 & 423 & 5997 & 4 \\
Long2 & 64455 & 1865 & 42740 & 402 & 5819 & 6 \\
Long3 & 54493 & 1715 & 36972 & 309 & 5116 & 4 \\
Long4 & 64455 & 1865 & 42740 & 402 & 5819 & 6 \\
Long5 & 51336 & 1652 & 35128 & 336 & 4853 & 4 \\
Long6_36 & 33759 & 1648 & 25141 & 474 & 1093 & 3 \\
Long6_48 & 64089 & 1970 & 42651 & 512 & 2605 & 1 \\
Long6_60 & 60819 & 1919 & 40559 & 502 & 2602 & 2 \\
Long6_72 & 51739 & 1764 & 34997 & 479 & 2242 & 3 \\
Long6_84 & 42231 & 1579 & 29257 & 461 & 1840 & 5 \\
Long7_12 & 23254 & 1431 & 18487 & 448 & 725 & 3 \\
Long7_24 & 58908 & 1883 & 39590 & 488 & 2431 & 2 \\
Long7_36 & 53011 & 1781 & 35997 & 473 & 2324 & 4 \\
Long7_48 & 32012 & 1340 & 22931 & 334 & 2955 & 2 \\
Long7_54 & 27900 & 1257 & 20239 & 335 & 2565 & 2 \\
\hline
\end{tabular}

Long1: total milk production in all lactations, in kg, Long2: number of lactations initiated, Long3: number of days in lactation, Long4: time from birth to the last milk recording, in months, Long5: time from the first calving to the last milk recording, in months, Long6_36, 48, 60, 72 and 84: survival from birth to 36, 48, 60, 72 and 84 months, respectively, Long7_12, 24, 36, 48, and 54: survival from the first calving to 12, 24, 36, 48 and 54 months, respectively

The statistical model used for estimation of variance components of longevity measures was represented by:

$$
y=x \beta+Z a+e
$$

where $y$ is the vector of observations of the longevity measures, $\beta$ is the vector of fixed effects (contemporary group, class of milk production at first lactation, age class at calving, plus the threshold effect for measures of survival), $a$ is the vector of random additive genetic effects, and $\boldsymbol{e}$ is the unknown vector of random residual effects, $X$ and $Z$ are incidence matrices that associate observations to fixed and random direct additive genetic effects, respectively.

The assumptions for the random additive genetic effects and residual threshold model were:

$$
\begin{aligned}
& a \mid G \sim N[0, G], \text { given } G=A \sigma_{a}^{2} \\
& e \mid R \sim N[0, R], \text { given } R=I \sigma_{e}^{2} \\
& G \mid u_{a} S_{a} \sim I W\left(u_{a} S_{a^{\prime}} u_{a}\right) \\
& R \mid u_{e} S_{e} \sim I W\left(u_{e} S_{e^{\prime}} u_{e}\right)
\end{aligned}
$$

where $G, R, A$, I are respectively, the matrices of variances of additive genetic effects, residual, kinship coefficient and identity; $\sigma_{a}^{2}$ is the additive genetic variance; $\sigma_{e}^{2}$ is the residual variance; IW is the inverted Wishart distribution; $u_{a}$ and $S_{a} ; u_{e}$ and $S_{e}$ are a priori values and degrees of freedom for direct additive and residual genetic variances, respectively. 
Measures of survival were threshold traits presumed to have an underlying continuous distribution. The threshold model relates to the response observed in the categorical scale with a normal underlying continuous scale. Assuming that the underlying scale (U) has a normal distribution:

$$
U \mid \theta \sim N\left(W \theta, I \sigma_{e}^{2}\right)
$$

where $\theta=\left(b^{\prime}, a^{\prime}\right)$ is the vector of parameters location with $b$ (defined from a frequentist point of view, as fixed effects); $a$ (random additive effect); $W$ is a known incidence matrix; I is an identity matrix, and $\sigma_{e}^{2}$ is the residual variance.

With the Bayesian analysis, it was assumed that the prior distributions for the residual and direct additive genetic effects follow multivariate normal distributions:

$$
\begin{aligned}
& p\left(a \mid \sigma_{a}^{2}\right) \sim N\left(0, A \sigma_{a}^{2}\right) \\
& p\left(e \mid \sigma_{e}^{2}\right) \sim N\left(0, l \sigma_{e}^{2}\right)
\end{aligned}
$$

where $A$ is the relationship matrix; $\sigma_{a}^{2}$ is the additive genetic variance, $/$ is an identity matrix. For $\sigma_{e}^{2}$ it was assumed residual variance equal to 1 (Gianola \& Foulley 1983).

The linkage between the two scales (categorical and continuous) can be unequivocally established, with the contribution of the probability of an observation being in the first category, being proportional to:

$$
P\left(y_{v}=0 \mid t, 0\right)=P\left(U_{v} \leq t \mid t, 0\right)=\Phi\left(\left(t-w_{v}^{\prime} \theta\right)\right)
$$

where $y_{v}$ is the response variable to $V^{\text {th }}$ observation, taking values 0 or 1 if the observation belongs to the first or second category, respectively, $t$ is the threshold value; $U_{v}$ is the value of underlying variable to the aforementioned observation, $\Phi$ is the cumulative distribution function of a normal standard variable and $w_{v}^{\prime}$ is a column vector of incidence that unites $\theta$ to $V^{\text {th }}$ observation.

\section{Results}

On average, cows produced $20994 \pm 12.81 \mathrm{~kg}$ of milk (Long1) throughout their productive life, ranging from 3064 to $59997 \mathrm{~kg}$. The number of lactations initiated ranged from one to seven, with an average of $2.7 \pm 1.45$ lactations per cow (Long2). The average days in lactation during productive life were $952 \pm 497.10$ days (Long3), with a 300 days minimum period and a maximum period of 2896 days. The mean length of time cows remained in the herd, from birth (Long4) or from the first calving (Long5) was from $60 \pm 19.32$ and $33 \pm 18.87$ months, respectively (Table 2).

The percentage of cows that failed to remain in the herd increased as the time period determined by the survival measures increased (Figure 1). There was a decrease from $93.31 \%$ (Long6_36) to $24.57 \%$ (Long6_84) in the survival rate from birth to 36 months and to 84 months, respectively.

The survival rates up to $12,24,36,48$ and 54 months after first calving were similar to the first survival measures from birth until culling. It was observed that 36 months after first calving (Long7_36), nearly $50 \%$ of the cows were no longer in the herd. The reduction from $94.56 \%$ (Long7_12) to $29.16 \%$ (Long7_54) indicates a lower ability of the cow to survive due to either voluntary or involuntary culling. 
Table 2

Means and standard deviations, minimum and maximum for longevity measures related to productive life

\begin{tabular}{lrrrr}
\hline & \multicolumn{1}{c}{ Mean } & Standard Deviation & Minimum & Maximum \\
\hline Long1 & 20994.61 & 12818.96 & 3064 & 59997 \\
Long2 & 2.68 & 1.45 & 1 & 7 \\
Long3 & 952.59 & 497.10 & 300 & 2896 \\
Long4 & 60.08 & 19.32 & 33 & 150 \\
Long5 & 33.45 & 18.87 & 3 & 122 \\
\hline
\end{tabular}

Long1: total milk production in all lactations, in kg, Long2: number of lactations initiated, Long3: number of days in lactation, Long4: time from birth to the last milk recording, in months, Long5: time from the first calving to the last milk recording, in months

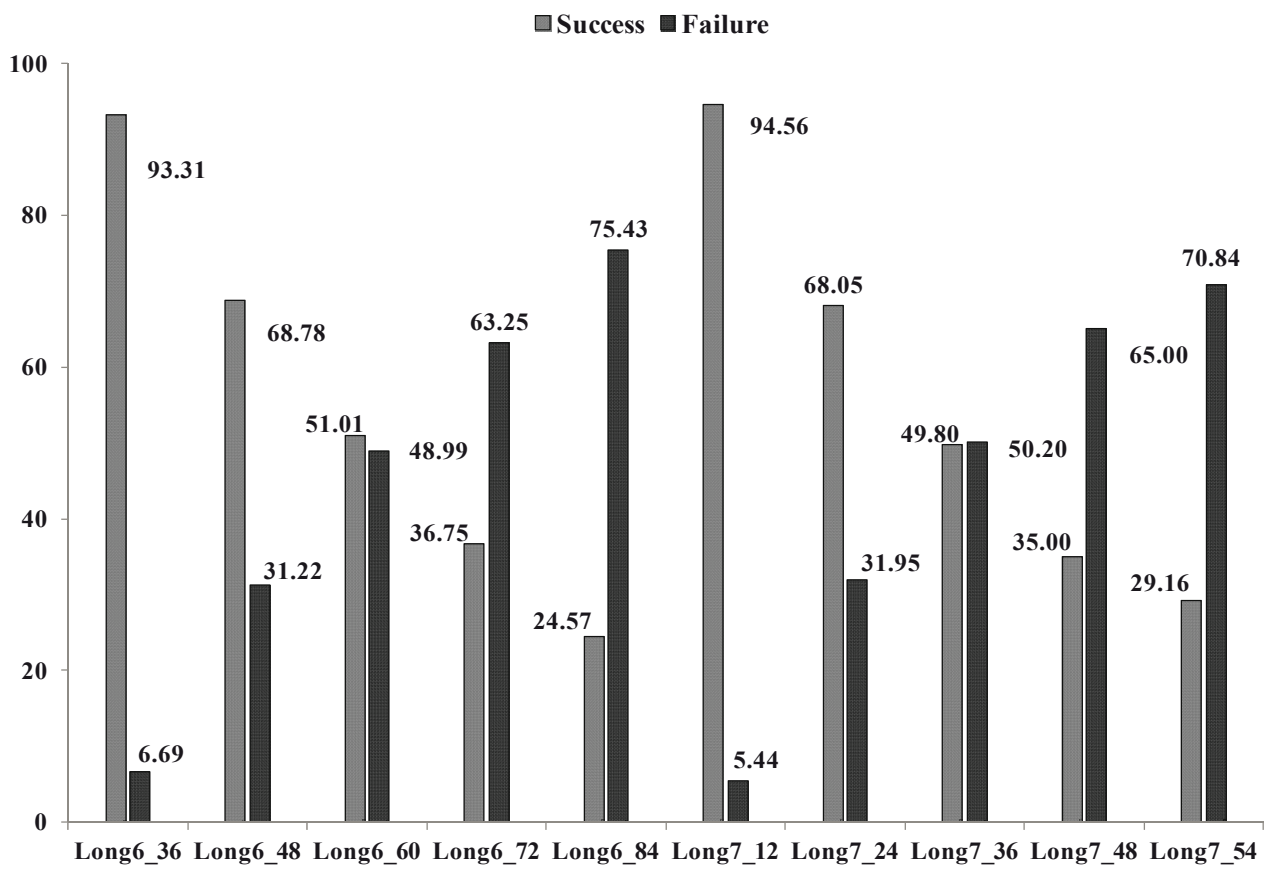

Figure 1

Percentage of success and failure to Long6_36, 48, 60, 72 and 84 (survival from birth to 36, 48, 60, 72 and 84 months, respectively); Long7_12, 24, 36, 48 and 54 (survival from the first calving to 12, 24, 36, 48 and 54 months, respectively).

Estimates of components of additive genetic variance for measures related to productive life (Long1 to Long5) were lower than the residual variances, with values ranging from 0.11 (Long2) to 622.68 (Long1) for the additive variance and 1.16 (Long2) to 9427.15 (Long1) for the residual variance (Table 3 ). Heritability of the measures related to productive life was low, with the highest estimate for Long2 $(0.09 \pm 0.007)$.

The number of cycles, burn-in period and number of samples of Markov chains were sufficient to achieve convergence of posterior distributions of the parameters of interest for survival measures, except Long7_24 which presented a value lower than $0.05 \%$ for the 
Table 3

Estimates of components of additive genetic variance $\left(\sigma_{a}^{2}\right)$, residual $\left(\sigma_{e}^{2}\right)$ and heritability $\left(\mathrm{h}^{2}\right)$ with its standard deviation to longevity measures related to productive life

\begin{tabular}{llllcc}
\hline Parameters & Long1 & Long2 & Long3 & Long4 & Long5 \\
\hline$\sigma_{a}^{2}$ & 622.689 & 0.116 & 1.152 & 16.990 & 16.260 \\
$\sigma_{e}^{2}$ & 9427.151 & 1.169 & 14.469 & 231.760 & 220.237 \\
$h^{2}$ & $0.06 \pm 0.006$ & $0.09 \pm 0.007$ & $0.07 \pm 0.006$ & $0.07 \pm 0.006$ & $0.07 \pm 0.007$ \\
\hline
\end{tabular}

Long1: total milk production in all lactations, in kg, Long2: number of lactations initiated, Long3: number of days in lactation, Long4: time from birth to the last milk recording, in months, Long5: time from the first calving to the last milk recording, in months

Table 4

A posteriori descriptive statistics from estimates of additive genetic $\left(\sigma_{a}^{2}\right)$ and residual $\left(\sigma_{e}^{2}\right)$, and heritability $\left(\mathrm{h}^{2}\right)$ for survival measures from birth

\begin{tabular}{|c|c|c|c|c|c|c|}
\hline Parameters & Mean \pm SD & Mode & Median & Min & Max & IC- $95 \%$ \\
\hline \multicolumn{7}{|l|}{ Long6_36 } \\
\hline$\sigma_{a}^{2}$ & $0.064 \pm 0.031$ & 0.112 & 0.056 & 0.008 & 0.193 & 0.009 to 0.123 \\
\hline $\begin{array}{l}a \\
\sigma_{e}^{2}\end{array}$ & $1.009 \pm 0.011$ & 1.011 & 1.009 & 0.972 & 1.048 & 0.987 to 1.030 \\
\hline$h^{e}$ & $0.061 \pm 0.027$ & 0.047 & 0.056 & 0.007 & 0.161 & 0.013 to 0.112 \\
\hline \multicolumn{7}{|l|}{ Long6_48 } \\
\hline$\sigma_{a}^{2}$ & $0.058 \pm 0.011$ & 0.051 & 0.058 & 0.024 & 0.094 & 0.037 to 0.079 \\
\hline $\begin{array}{l}a \\
\sigma_{e}^{2}\end{array}$ & $1.025 \pm 0.008$ & 1.028 & 1.029 & 1.002 & 1.057 & 1.012 to 1.043 \\
\hline$h^{e}$ & $0.053 \pm 0.009$ & 0.044 & 0.054 & 0.023 & 0.083 & 0.036 to 0.072 \\
\hline \multicolumn{7}{|l|}{ Long6_60 } \\
\hline$\sigma_{a}^{2}$ & $0.095 \pm 0.124$ & 0.100 & 0.094 & 0.055 & 0.157 & 0.071 to 0.118 \\
\hline$\sigma_{e}^{a}$ & $1.033 \pm 0.008$ & 1.031 & 1.033 & 0.997 & 1.062 & 1.016 to 1.048 \\
\hline$h^{e}$ & $0.082 \pm 0.010$ & 0.091 & 0.083 & 0.051 & 0.130 & 0.064 to 0.103 \\
\hline \multicolumn{7}{|l|}{ Long6_72 } \\
\hline$\sigma_{a}^{2}$ & $0.125 \pm 0.015$ & 0.121 & 0.125 & 0.078 & 0.187 & 0.097 to 0.158 \\
\hline$\sigma_{\rho}^{2}$ & $1.032 \pm 0.009$ & 1.033 & 1.032 & 1.000 & 1.066 & 1.014 to 1.049 \\
\hline$h^{e}$ & $0.112 \pm 0.012$ & 0.091 & 0.107 & 0.071 & 0.154 & 0.086 to 0.133 \\
\hline \multicolumn{7}{|l|}{ Long6_84 } \\
\hline$\sigma_{a}^{2}$ & $0.142 \pm 0.020$ & 0.135 & 0.141 & 0.071 & 0.220 & 0.104 to 0.183 \\
\hline $\begin{array}{l}a \\
\sigma_{e}^{2}\end{array}$ & $1.028 \pm 0.010$ & 1.028 & 1.028 & 0.991 & 1.070 & 1.009 to 1.047 \\
\hline$h^{e}$ & $0.124 \pm 0.015$ & 0.120 & 0.120 & 0.069 & 0.174 & 0.091 to 0.150 \\
\hline
\end{tabular}

Long6_36, 48, 60, 72 and 84 : survival from birth to $36,48,60,72$ and 84 months, respectively

Geweke's test. Moreover, the estimated mean, median and mode of the variance components and heritability, with the exception of measures Long6_36 and Long7_12, were similar, showing that the posterior distributions of these parameters were relatively symmetric (Table 4 and Table 5).

All measurements assessed relate to the longevity of animals, even though represented by different mathematical expressions. Likewise, the measures related to productive life and survival measures showed low additive genetic variance. The additive genetic and residual variances for survival from birth to culling ranged respectively from 0.058 (Long6_48) to 0.142 (Long6_84); from 1.009 (Long6_36) to 1.033 (Long6_60) (Table 4); and for survival from first calving to culling from 0.053 (Long7_24) to 0.230 (Long7_54); from 1.010 (Long7_12) to 1.072 (Long7_48) (Table 5). 
Table 5

A posteriori descriptive statistics from estimates of additive genetic $\left(\sigma_{a}^{2}\right)$ and residual $\left(\sigma_{e}^{2}\right)$ variances and heritability $\left(\mathrm{h}^{2}\right)$ for survival measures from the first calving

\begin{tabular}{lllllll}
\hline Parameters & Mean \pm SD & Mode & Median & Min & Max & IC- $95 \%$ \\
\hline $\begin{array}{c}\text { Long7_12 } \\
\sigma_{a}^{2}\end{array}$ & $0.061 \pm 0.034$ & 0.101 & 0.056 & 0.005 & 0.220 & 0.006 to 0.110 \\
$\sigma_{e}^{2}$ & $1.010 \pm 0.013$ & 1.012 & 1.010 & 0.963 & 1.060 & 0.985 to 1.036 \\
$\mathrm{~h}^{2}$ & $0.061 \pm 0.029$ & 0.046 & 0.052 & 0.005 & 0.179 & 0.006 to 0.110 \\
Long7_24 & & & & & & \\
$\sigma_{a}^{2}$ & $0.053 \pm 0.009$ & 0.055 & 0.054 & 0.022 & 0.087 & 0.034 to 0.072 \\
$\sigma_{e}^{2}$ & $1.031 \pm 0.008$ & 1.033 & 1.031 & 1.001 & 1.066 & 1.015 to 1.047 \\
$\mathrm{~h}^{2}$ & $0.052 \pm 0.007$ & 0.051 & 0.049 & 0.020 & 0.078 & 0.032 to 0.066 \\
Long7_36 & & & & & & \\
$\sigma_{a}^{2}$ & $0.080 \pm 0.011$ & 0.101 & 0.080 & 0.046 & 0.129 & 0.059 to 0.090 \\
$\sigma_{e}^{2}$ & $1.036 \pm 0.008$ & 1.037 & 1.037 & 1.003 & 1.072 & 1.019 to 1.053 \\
$\mathrm{~h}^{2}$ & $0.070 \pm 0.009$ & 0.075 & 0.071 & 0.042 & 0.111 & 0.053 to 0.090 \\
Long7_48 & & & & & & \\
$\sigma_{a}^{2}$ & $0.211 \pm 0.028$ & 0.204 & 0.210 & 0.126 & 0.317 & 0.156 to 0.266 \\
$\sigma_{e}^{2}$ & $1.072 \pm 0.012$ & 1.077 & 1.072 & 1.029 & 1.121 & 1.048 to 1.094 \\
$\mathrm{~h}^{2}$ & $0.162 \pm 0.018$ & 0.166 & 0.164 & 0.105 & 0.227 & 0.128 to 0.200 \\
Long7_54 & & & & & & \\
$\sigma_{a}^{2}$ & $0.230 \pm 0.033$ & 0.224 & 0.229 & 0.119 & 0.399 & 0.167 to 0.298 \\
$\sigma_{e}^{2}$ & $1.066 \pm 0.012$ & 1.065 & 1.066 & 1.015 & 1.114 & 1.040 to 1.089 \\
$\mathrm{~h}^{2}$ & $0.180 \pm 0.021$ & 0.166 & 0.177 & 0.101 & 0.272 & 0.136 to 0.218 \\
\hline
\end{tabular}

Long7_12, 24, 36, 48, and 54: survival from the first calving to $12,24,36,48$ and 54 months, respectively

The heritability estimates for survival measures, in general, were low, for both survival from birth (Table 4) and survival from first calving to culling (Table 5). The highest heritability was observed for Long6_84, Long7_48 and Long7_54 months, with values of 0.12, 0.16 and 0.18, respectively. Furthermore, it was observed that heritability increased as time used in the measurement increased, determined by survival measures obtained from birth and from first calving to culling.

\section{Discussion}

The evolution of Brazilian milk production has grown continuously over the past few years, and, as a result, there has been an increase in costs, which in turn has led to a reduction in profitability (IBGE 2011). Longevity is important in the dairy industry as herds with longerlived cows, show greater opportunity to return revenue (Queiroz et al. 2007), but also show a lower number of replacements, and consequent decrease in involuntary culling, increasing culling related to milk production which results in herds with higher genetic merit for milk production (Lagrotta et al. 2010).

The average observed for Long2 (2.7), Long4 (60.08 months) and Long5 (33.45 months) were similar to those reported for Holstein cows in other countries. Tsuruta et al. (2005) in the United States reported on an average of 2.8 lactations (Long2). In Iran, Nilforooshan \& Edriss (2004) reported on values of 57.2 and 30.1 months, respectively for Long4 and Long5. Higher performances were observed in Simmental dairy cows by Strapák et al. (2011) with a value of 3.4 for Long2, as well as by Jovanovac \& Raguz (2011) for Long4 (72 months) and Long5 (47.52 
months). Differences among the studies for higher or lower longevity can be attributed to genetic and/or environmental differences between the herds.

Increases in the number of longer-lived animals are expected to be accompanied by higher milk production and decreased involuntary culling. According to Forabosco et al. (2009) longer-lived animals can be controlled by lower incidence of reproductive problems, health status, body conformation and low milk production. In addition, Long1 and Long5 cover much of the animal's life and may be used for evaluation of the economic efficiency of a production system as they include reproductive, productive and cost criteria.

Increases in the percentage of cows that failed to remain in the herd until the period determined by survival measures (Long6_36 to Long6_84 and Long7_12 to Long7_54) highlight the difficulties faced by Brazilian farmers in maintaining cows with good performance, both productive and reproductive, with the passage of time (Queiroz et al. 2007). This was expected because, with increasing age of the animal, the farmers may have more production information to identify their best cows and thus select them with more confidence.

Long1 to Long5, Long6_36 to Long6_84, and Long7_12 to Long7_54 are alternative measures to express longevity and each has its merits for selection, such as the length of the period necessary for obtaining measurements of productive life and the partial information of life provided by measures of survival. In this case, deleting records from living cows or considering them as dead or culled, may lead to biased results in estimates of genetic values (Vollema et al. 2000). However, as they are obtained before the death of the animal, the use of survival measures may be an alternative to reduce generation intervals and enable higher genetic progress for longevity (Galeazzi et al. 2010).

The high estimates of residual variance, low estimates of additive genetic variance and hence low heritability found for Long1 to Long5 indicate that they are highly influenced by environmental factors and thus direct selection for these traits would result in low genetic gains for the population. However, these gains can be obtained by improving the environment in which the animals are maintained. The heritability reported in the literature for different measures of longevity in Holstein dairy cows reared under temperate climate conditions was also low, ranging from 0.02 to 0.10 (Vollema \& Groen 1996, Tsuruta et al. 2005).

Additionally, these measures are obtained only after the death or culling of animals, which may increase the generation interval (Galeazzi et al. 2010) and hinder the use of young bulls. These, on principle, have higher genetic values than older bulls in a breeding program, but due to their low use and accuracy at a young age will be underutilized.

The longevity measures analysed by the linear model (Long1 to Long5) showed lower heritability compared with those analysed by the threshold model (Long6_36 to Long6_84 and Long7_12 to Long7_54), with values ranging from 0.06 to 0.09 and 0.05 to 0.18 , respectively. The highest heritability estimates for survival measures Long6_84 (0.12), Long7_48 (0.16) and Long7_54 (0.18) compared to measures of productive life underscore observations in the literature on higher heritability obtained with the use of threshold models in contrast to the linear model (Sousa et al. 2000). These differences in heritability may be caused by intrinsic differences in longevity measures related to productive life and survival.

The low heritability observed for longevity may be due to the exclusion of cows' censored analyses. With the use of survival models Forabosco et al. (2006) reported that the heritability 
of longevity showed a slight decrease when no censorship records were used. According to these authors, the decrease may have been caused by the loss of genetic variation with the elimination of censored records.

Comparisons between linear and survival models indicate that the survival model results in higher estimates of heritability for longevity (Ducrocq et al. 1988, Forabosco et al. 2006). This may be due to the inclusion of censored data and time-dependent variables, making it an effective tool in the analysis of the longevity in dairy cattle, as environmental and management conditions that affect a cow often change over time (Forabosco et al. 2006).

Although survival analysis was not included in the present study, it may be considered more appropriate for traits with censored data such as longevity. Nevertheless, the present study is pioneering in Brazil, generating initial parameters for future use of this and other methods for implementation of genetic evaluation for longevity in Holstein cows in Brazil.

Despite survival being measured in a manner similar to longevity, observing the absence or presence of the cow in certain period of life leads to lower heritability for survival from birth to a certain period ( 0.05 to 0.12 ), in contrast to survival from first calving (0.05 to 0.18 ). This can be justified by the fact that they are measured considering different periods in the cow's life, from birth or first calving, while survival obtained from first calving could be more involved with the productive period, since all measures have been adjusted for milk production in the first lactation.

Adjusting (or not) longevity for milk production during first lactation depends on the objective of selection (Galeazzi et al. 2010). When corrected for this effect, the cow's ability to delay involuntary culling is measured, excluding problems related to udder ligaments, diseases and infertility matters (Vukasinovic et al. 1995), and, as a result raises, the emphasis based on milk production, so-called voluntary culling.

The highest heritabilities for survival were observed in older age groups (Long6_84 (0.12), Long7_48 (0.16) and Long7_54 (0.18)) suggesting that these may result in increased genetic progress per generation. As these measures are obtained later in the animal's life compared to other survival measures, it is important to seek a balance between the generation interval and a possible greater genetic gain obtained by the use of measures with higher heritability. As heritability is similar but a longer time is needed to obtain Long7_54, Long7_48 can be considered as the most suitable for selection in Brazilian herds, as it is obtained earlier in the animal's life in comparison with other measures.

An increase in the heritability with increasing period for survival indicates that, as the cow matures, the environmental influence decreases, a trend also observed by Vukasinovic et al. (1995), Groen \& Vollema (1996) and Ahlman et al. (2011) in dairy cattle.

No studies were found in the Brazilian literature on survival measures assessing Holstein herds in tropical climate conditions, analysed with the threshold model. Similar results for Long7_12 (0.05), Long7_24 (0.08) and higher values for Long7_36 (0.20) were observed for Holstein cows in Sweden (Ahlman et al. 2011) using the threshold model.

The indirect selection for traits correlated with longevity, for instance linear type traits, can be the most suitable in comparison direct selection because these traits can be measured earlier in the animal's life and show larger heritability estimates that longevity (Daliri et al. 2008). These traits may be promise alternatives for obtaining faster genetic progress for longevity. It is important to verify the genetic associations between longevity and other 
characteristics that aid in the identification of longer-lived animals in tropical Brazilian herds. In conclusion, measures of survival assessed in later periods of the cow's life showed higher heritabilities compared to measures such as survival and those related to productive life. However, they show a low potential for response to selection. Survival from first calving to 48 months was the most efficient measure in detecting genetic variability of animals, this being indicated for use in future genetic evaluations of Holstein cattle in Brazil.

\section{Acknowledgements}

The authors thank the Brazilian Association of Holstein Cattle Breeders (ABCBRH) for supplying the data, which were essential for development of this study, and we also thank the Coordination of Improvement of Higher Education Personnel (CAPES) for granting the scholarship.

\section{References}

Ahlman T, Berglund B, Rydhmer L, Strandberg E (2011) Culling reasons in organic and conventional dairy herds and genotype by environment interaction for longevity. J Dairy Sci 94, 1568-1575

Berry DP, Harris BL, Winkelman AM, Montgomerie W (2005) Phenotypic Associations Between Traits Other than Production and Longevity in New Zealand Dairy Cattle. J Dairy Sci 88, 2962-2974

Boldman KG, Kriese LA, Van Vleck LD, Van Tassell CP, Kachman SD (1995) A Manual for Use of MTDFREML: A Set of Programs to Obtain Estimates of Variances and Covariances. U.S. Department of Agriculture, Agricultural Research Service ftp://aipl.arsusda.gov/pub/outgoing/mtdfreml/mtdfrman.pdf [last accessed 29.08.2014]

Caetano SL, Rosa GJM, Savegnago RP, Ramos SB, Bezerra LAF, Lôbo RB, de Paz CCP, Munari DP (2012) Characterization of the variable cow's age at last calving as a measurement of longevity by using the Kaplan-Meier estimator and the Cox model. Animal 7, 540-546

Cruickshank J, Weigel KA, Dentine MR, Kirkpatrick BW (2002) Indirect Prediction of Herd Life in Guernsey Dairy Cattle. J Dairy Sci 85, 1307-1313

Daliri Z, Hafezian SH, Shad Parvar A, Rahimi G (2008) Genetic Relationships among Longevity, Milk Production and Linear Type Traits in Iranian Holstein Cattle. J Anim Vet Adv 7, 512-515

Ducrocq V, Quaas RL, Pollak EJ, Casella G (1988) Length of Productive Life of Dairy Cows. 2. Variance Component Estimation and Sire Evaluation. J Dairy Sci 71, 3071-3079

Forabosco F, Bozzi R, Filippini F, Boettcher P, Van Arendonk JAM, Bijma P (2006) Linear model vs. survival analysis for genetic evaluation of sires for longevity in Chianina beef cattle. Livest Sci 101, 191-198

Forabosco F, Jakobsen JH, Fikse WF (2009) International genetic evaluation for direct longevity in dairy bulls. J Dairy Sci 92, 2338-2347

Galeazzi PM, Mercadante MEZ, Silva JAIIV, Aspilcueta-Borquis RR, Camargo GMF, Tonhati H (2010) Genetic parameters for stayability in Murrah buffaloes. J Dairy Res 77, 252-256

Geweke J (1992) Evaluating the accurary of sampling-based approaches to the calculation of posterior moments. In: Bernardo JM, Berger JO, Dawid AP, Smit AFM (eds.) Bayesian statistics. 4. Proceedings of the 4th Valencia international meeting held in Peñíscola, Spain, April 15-20, 1991, New York, NJ, USA, 169-193

Gianola D, Foulley JL (1983) Sire evaluation for ordered categorical data with a threshold model. Genet Sel Evol 15, 201-224

Harville DA, Mee RW (1984) A Mixed-Model Procedure for Analyzing Ordered Categorical Data. Biometrics 40, 393-408

Heidelberger P, Welch PD (1983) Simulation Run Length Control in the Presence of an Initial Transient. Oper Res 31, 1109-1144 
IBGE (2012) [IBGE Indicators: Statistics of livestock production - December 2012]. Instituto Brasileiro de Geografia e Estatística (IBGE). Available at: http://www.ibge.gov.br/home/estatistica/indicadores/ agropecuaria/producaoagropecuaria/abate-leite-couro-ovos_201203_publ_completa.pdf [last accessed 29.08.2014] [in Portuguese]

Jovanovac S, Raguž N (2011) Analysis of the Relationships Between Type Traits and Longevity in Croatian Simmental Cattle Using Survival Analysis. Agric Conspec Sci 76, 249-253

Lagrotta MR, Euclydes RF, Verneque RS, Santana Júnior ML, Pereira RJ, Torres RA (2010) [Relationship between morphological traits and milk yield in Gir breed cows]. Pesq Agropec Bras 45, 423-429 [in Portuguese]

Misztal I, Tsuruta S, Strabel T, Auvray B, Druet T, Lee DH (2002) BLUPF90 and related programs (BGF90). In: Proc 7th World Congr Genet Appl Livest Prod, Montpellier, France communication 28-07

Nilforooshan MA, Edriss MA (2004) Effect of Age at First Calving on Some Productive and Longevity Traits in Iranian Holsteins of the Isfahan Province. J Dairy Sci 87, 2130-2135

Pérez-Cabal MA, García C, Gonzàlez-Recio O, Alenda R (2006) Genetic and Phenotypic Relationships Among Locomotion Type Traits, Profit, Production, Longevity, and Fertility in Spanish Dairy Cows. J Dairy Sci 89, 1776-1783

Queiroz SA, Figueiredo G, Silva JAIIV, Espasandin AC, Meirelles SL, Oliveira JA (2007) [Estimates of genetic parameters of stayability in Caracu cattle]. Rev Bras Zootec 36, 1316-1323 [in Portuguese]

Roso VM, Schenkel FS (2006) AMC - a computer programme to assess the degree of connectedness among contemporary groups. In: Proc 8th World Congr Genet Appl Livest Prod, Belo Horizonte, MG, Brazil, communication Nr. 26-27

Smith BJ (2005) Bayesian output analysis program (BOA) Version 1.1 user's manual. lowa State University, lowa City, IA, USA. Available at: http://www.public-health.uiowa.edu/boa/BOA.pdf. [last accessed 29.08.2014]

Sousa WH, Pereira CS, Bergmann JAG, Silva FLR (2000) [Estimates of variance components and genetic parameters for reproductive traits by means of linear and threshold models]. Rev Bras Zootec 29, 22372247 [in Portuguese]

Strapák P, Juhás P, Strapáková E (2011) The relationship between the length of productive life and the body conformation traits in cows. J Cent Eur Agr 12, 239-254

Tsuruta S, Misztal I, Lawlor TJ (2005) Changing Definition of Productive Life in US Holsteins: Effect on Genetic Correlations. J Dairy Sci 88, 1156-1165

Vacek M, Štípková M, Němcová E, Bouška J (2006) Relationships between conformation traits and longevity of Holstein cows in the Czech Republic. Czech J Anim Sci 51, 327-333

Vollema AR, Groen AF (1996) Genetic Parameters of Longevity Traits of an Upgrading Population of Dairy Cattle. J Dairy Sci 79, 2261-2267

Vollema AR, Van Der Beek S, Harbers AGF, De Jong G (2000) Genetic Evaluation for Longevity of Dutch Dairy Bulls. J Dairy Sci 83, 2629-2639

Vukašinović N, Moll J, Künzi N (1995) Genetic relationships among longevity, milk production, and type traits in Swiss Brown cattle. Livest Prod Sci 41, 11-18

Wall E, White IMS, Coffey MP, Brotherstone S (2005) The Relationship Between Fertility, Rump Angle, and Selected Type Information in Holstein-Friesian Cows. J Dairy Sci 88, 1521-1528 